Facilitated by Wendy Child of Campbell Communications, each group brought together 10-15 association members and focused on the kinds of initiatives needed to support political scientists in the next century.

Each group expressed concern about the growing need for assistance to graduate students and faculty at less endowed institutions. Participants also called for continued APSA participation in the fight against cuts to education funding.

Campbell Communications' report on the discussion groups will be used to direct APSA's resources where they are most needed and develop goals and strategies for the association's Centennial Campaign.

\section{Political Science Chairs Recommend Strategies to Counter Decreases in Undergraduate Enrollments}

A session devoted to exploring sources of and responses to declining undergraduate political science course enrollments was held on August 28 during the Conference for Chairs at the APSA Annual Meeting in San Francisco. The session provided department chairs with data collected by the Association in its annual survey of departments. It also gave chairs the opportunity to exchange ideas on how to attract students to political science courses and encourage them to major in the discipline.

Gary Klass, who initiated the discussion of enrollment trends on the PSRT-L last spring, distributed data on enrollments in Illinois. For the APSA, Sheilah Mann provided updated and enlarged graphs tracking decreases in undergraduate enrollments and majors for the categories of departments represented in the Association's Annual Surveys. These data were presented in full in the last issue of PS: Political Science \& Politics (Mann 1996).

The 91 participants at the session concurred that decreasing student interest in political science is widespread. The possible causes of this development, also identified in the September PS: Political Science \&
Politics, were reviewed. Several department chairs emphasized declining interest in public affairs, disillusionment with politics, and the denigration of public service as factors taking a toll on the discipline's appeal. Some participants recommended that the profession respond by raising the level of discourse about politics and government, and by attempting to counter negative public perceptions of politics and politicians.

Some participants argued that political science departments should assert the importance of their courses for teacher preparation, and even consider designing courses specifically for training pre-college teachers. The U.S. Department of Education has released figures projecting growth in school enrollments, with a predicted increase of $15 \%$ in high school enrollments by 2006 . The expansion of the student population is expected to be matched by a $16 \%$ growth in the number of high school teachers. Regional variations in school enrollment growth are projected as well: $21 \%$ in the West, $10 \%$ in the South, $4 \%$ in the Northeast and 3\% in the Midwest (1996, U.S. Department of Education).

Participating chairs offered additional suggestions about introductory courses for non-majors. One example is a course in world politics designed to prepare students to be continually informed about international events and developments. There was a consensus that the introductory courses in the discipline are especially important and should be given more attention. These are the courses that introduce political science to students, provide needed instruction about government and public affairs to students in pre-professional programs such as business, journalism, engineering, and education, and also serve to recruit majors. Some departments reported making a special effort to provide smaller-sized sections in these courses and assigning them to effective teachers. Some departments also reported inviting the students who do well in the introductory courses to major in political science.

Peter Zwick, California State University at San Marcos advised departments to learn what interests students and then respond to such interests. His comment was followed with observations that students and their parents are especially concerned about employment prospects, and departments must therefore provide instructional formats such as internships, and simulations of organizations like the model U.N. and model state legislature programs. Ron Peters, University of Oklahoma, reported that his department offers a one-credit course on careers in political science.

Lyman Sargent noted that his department at the University of Missouri, St. Louis introduced several strategies to appeal to students, but still experienced enrollment declines. Participants agree that further examination is still needed to uncover the sources of the decline, including the examination of departments not recording lower undergraduate enrollments or fewer majors.

The Association will try to collect this information in the coming year and invites departments to submit descriptions of programs and courses that attract students and meet special needs.

\section{Committee Suggestions Welcomed}

The APSA welcomes suggestions for individuals interested in serving on APSA Standing Committees for terms beginning in January 1, 1998. These appointments vary from one to three years and include award committees, PS Editorial Board, and a host of others. A listing of committees and their area of responsibility can be found in the March 1996 issue of PS. These positions are held on a volunteer basis. Interested members should make their suggestions by mail, to PresidentElect M. Kent Jennings, c/o the National Office at 1527 New Hampshire Ave., NW, Washington, DC 20036 or e-mail at rudder@apsa.com. 